\title{
Role of Thyroglobulin, Neck Ultrasound, Thyroglobulin Antibodies Trend and Diagnostic Whole Body Scan in the Management of Differentiated Thyroid Cancer Patients with Persistent Thyroglobulin Antibodies
}

\author{
Laura Agate, Loredana Lorusso, Paolo Piaggi, Francesca Bianchi, Federica Brozzi, Pierina Santini, Eleonora Molinaro, Paolo Vitti, and Rossella Elisei \\ ${ }^{1}$ Endocrinology Unit, Department of Clinical and Experimental Medicine, University of Pisa, Via Paradisa 2, 56124 Pisa, Italy \\ "Corresponding author: Rossella Elisei, Endocrinology Unit, Department of Clinical and Experimental Medicine, University of Pisa, Via Paradisa 2, 56124 Pisa, Italy,
} Tel: +39-050-995120, Fax:+39-050-578772; E-mail: rossella.elisei@med.unipi.it

*Dr. Laura Agate and Dr. Lorusso Loredana are first co-authors and have equally contributed to the study.

Received date: November 09, 2016; Accepted date: November 24, 2016; Published date: November 30, 2016

Copyright: (c) 2016 Agate L, et al. This is an open-access article distributed under the terms of the Creative Commons Attribution License, which permits unrestricted use, distribution, and reproduction in any medium, provided the original author and source are credited.

\begin{abstract}
Background: During the follow-up of differentiated thyroid cancer patients, the presence of thyroglobulin antibodies makes thyroglobulin measurements unreliable. For this reason, thyroglobulin antibodies measurement and the evaluation of their titer trend are also recommended.
\end{abstract}

Objective: We aimed to identify the best method among stimulated thyroglobulin, thyroglobulin antibodies titer trend, neck ultrasound and diagnostic whole body scan for detecting the presence of disease in a group of differentiated thyroid cancer patients with thyroglobulin antibodies.

Patients and methods: We retrospectively reviewed the data of 212 consecutive differentiated thyroid cancer patients with thyroglobulin antibodies referred to us between 2005 and 2007 for performing a diagnostic whole body scan. All patients were evaluated during the first two years after the initial treatment.

Results: Diagnostic whole body scan sensitivity and specificity in detecting persistent diseases were $70 \%$ and $72 \%$, respectively. Diagnostic whole body scan alone had the best positive and negative predictive values (93\% and $32 \%$, respectively). A low sensitivity and specificity (56\% and $10 \%$, respectively) for increasing or stable thyroglobulin antibodies titer trends were also identified. A good compromise between sensitivity and specificity was obtained when diagnostic whole body scan, stimulated thyroglobulin and neck ultrasound were combined without considering thyroglobulin antibodies trend evaluations ( $82 \%$ and $45 \%$, respectively).

Conclusions: Diagnostic whole body scan plays an important role in detecting persistent disease in differentiated thyroid cancer patients with thyroglobulin antibodies, both alone and in association with other methods. However, its low negative predictive value suggests that when a suspicious persistent disease is present, the use of other imaging methods, such as computed tomography scan or FDG-positron emission computed tomography, is recommended. Finally, from this study, it appears that the thyroglobulin antibodies titer trend does not add any useful information about the disease status in the first two years after initial treatment.

Keywords: Differentiated thyroid cancer; Thyroglobulin antibodies; Diagnostic whole body scan; Thyroglobulin

Abbreviations: DTC: differentiated thyroid cancer; TgAb: thyroglobulin antibodies: Tg: thyroglobulin; US: neck ultrasound; $\mathrm{dx}$ WBS: diagnostic whole body scan; PPV: positive predictive value; NPV: negative predictive value; rh-TSH: recombinant human thyroid stimulating hormone; pt-WBS: post high 131I activity whole body scan.

\section{Introduction}

The presence of serum thyroglobulin antibodies (TgAb) has been reported in approximately $25 \%$ of patients with differentiated thyroid cancer (DTC) [1,2] and in only $10 \%$ of the general population [3]. During DTC patient follow-up, the presence of TgAb makes thyroglobulin ( $\mathrm{Tg}$ ) measurements unreliable because it either underestimates $\mathrm{Tg}$ levels when common $\mathrm{Tg}$-immunometric assays
(IRMA) are used or overestimates Tg levels when less common Tgradioimmunoassay methods (RIA) are employed $[4,5]$. To reduce but not eliminate the presence of the above-described interference, the current guidelines for the management of DTC patients strongly recommend the measurement of $\mathrm{TgAb}$ with every measurement of $\mathrm{Tg}$, ideally in the same laboratory and using the same assay [6,7].

It is conceivable that the presence of benign/metastatic thyroid tissue is the reason for the persistent synthesis of $\operatorname{TgAb}[8,10]$. Thus, in patients with DTC and TgAb positive, antibody titer may be used as an imprecise surrogate for persistent thyroid tissue as either normal or tumoral [11]. According to this concept, a decrease in the $\mathrm{TgAb}$ titer trend can be interpreted as a reduction in the residual disease, with no further imaging methods [except neck ultrasound (US)] being required. In contrast, when an increasing or stable titer trend is identified, in addition to neck US, an ${ }^{131} \mathrm{I}$ (or if available 123I or 124I) diagnostic whole-body scan (dx-WBS) can be helpful for identifying persistent or recurrent disease $[6,11]$. However, the practical usefulness 
Citation: Agate L, Lorusso L, Piaggi P, Bianchi F, Brozzi F, et al. (2016) Role of Thyroglobulin, Neck Ultrasound, Thyroglobulin Antibodies Trend and Diagnostic Whole Body Scan in the Management of Differentiated Thyroid Cancer Patients with Persistent Thyroglobulin Antibodies. J Nucl Med Radiat Ther 7: 317. doi:10.4172/2155-9619.1000317

Page 2 of 7

of $\mathrm{dx}$-WBS is still a matter of discussion, particularly in patients without $\operatorname{TgAb}$ but also in those with $\operatorname{TgAb}$ as there are some studies showing that dx-WBS is a prognostically and diagnostically useful procedure $[12,13]$ and others showing that it is less usefull $[14,15]$.

In this study, we evaluated the diagnostic accuracy of dx-WBS performed 6 months after radioiodine ablation in 212 DTC patients with TgAb. dx-WBS specificity, sensitivity, positive and negative predictive values (PPV and NPV, respectively) were also calculated and compared with those of stimulated $\mathrm{Tg}, \mathrm{TgAb}$ titer trends and neck US to identify which among them represents the best method for detecting the presence of persistent disease or thyroid remnants, as assessed by post-therapeutic whole body scan (pt-WBS) performed 4-6 months after dx-WBS.

\section{Patients and Methods}

\section{Patients}

We retrospectively reviewed the clinical and pathological data of 212 consecutive patients, including 169 females (80\%) and 43 males (20\%) (M:F=1:4), with DTC and TgAb referred to the Department of Endocrinology in Pisa between 2005 and 2007 for ${ }^{131} \mathrm{I} \mathrm{dx}$-WBS after recombinant human thyroid stimulating hormone (rh-TSH) administration (204 patients, 96\%) or thyroid hormone withdrawal (8 patients, $4 \%$ ). The mean age at diagnosis of all patients was $41 \pm 13.7$ years (range: 9-77 years; median: 40 years).

The histotype was papillary in 210 patients (99\%) and follicular in the remaining 2 cases (1\%). Histological variant information regarding papillary histotype patients were available for $159 / 212$ patients $(75 \%)$ : 69 patients had the classical variant (43\%), 45 had the follicular variant (28\%) and the remaining 45 patients had less frequent histological and more aggressive variants (29\%).

Despite the presence of serum $\operatorname{TgAb}$ in all cases (criteria for inclusion in the study group), the presence of focal or diffuse histological thyroiditis was identified in 107 patients (50\%). At the time of diagnosis, lymph node metastases were found in $84 / 212$ patients (40\%).

All selected patients underwent treatment according to our traditional protocol that requires a total thyroidectomy [141 patients (66.7\%) underwent thyroidectomy at the Department of Surgery of Pisa, 71 patients $(33.3 \%)$ were referred to our Department after have the surgery performed elsewhere], followed by remnant thyroid ablation with $1,110 \mathrm{MBq}$ to $3,700 \mathrm{MBq}$ of ${ }^{131} \mathrm{I}$.

Approximately 6 months after the radio-iodine (131I) ablation, patients were examined through a clinical and hormonal assessment, neck ultrasound and $\mathrm{dx}$-WBS to establish the subsequent follow-up. A subgroup of 68 of the 212 patients $(32 \%)$ underwent one or further radiometabolic treatment(s) with high ${ }^{131} \mathrm{I}$ activity according to the results of the first control performed 6 months after the initial treatment.

The study was approved by the Institutional Reviewing Board and all patients gave consent to participate in the study.

\section{Methods}

\section{$\mathrm{Tg}$ measurement}

Serum Tg measurement, either after L-T4 withdrawal or rh-TSH administration, was performed in the same laboratory for all patients.
A sensitive immunometric method with a functional sensitivity of 0.9 ng/ml (Immulite 2000 Thyroglobulin, Diagnostic Product Corporation, Los Angeles, CA) was used.

$\mathrm{Tg}$ stimulation was performed via administration of rh-TSH [one injection of rh-TSH (0.9 mg i.m.; Thyrogen, Genzyme Corp., Cambridge, MA) for 2 consecutive days] and in a small percentage of cases by withdrawing L-T4 therapy one month before evaluation.

TSH and Tg serum sample measurements were collected before the first rh-TSH injection and during the following days up to day 5 .

\section{$\mathrm{TgAb}$ and $\mathrm{TgAb}$ titer trend evaluation measurements}

The circulating $\mathrm{TgAb}$ measurement was determined in the same laboratory for all patients using an immunofluorimetric method (AIAPack TgAb Tosoh Corporation, Tokyo, Japan) [normal range: $0 \mathrm{U} / \mathrm{ml}$ to $30 \mathrm{U} / \mathrm{ml}$, coefficient of variation $(\mathrm{CV})$ varying between $10.5 \%$ and $17.7 \%$ depending on the titer].

In our study, we considered $\mathrm{TgAb}<20 \mathrm{IU} / \mathrm{ml}$ a negative titer after we had demonstrated in our laboratory that the interference of $\mathrm{TgAb}$ in the $\mathrm{Tg}$ assay begin when the $\mathrm{TgAb}$ values were $>20 \mathrm{IU} / \mathrm{ml}$ (data not shown).

To define an increasing or decreasing $\mathrm{TgAb}$ titer trend, we considered a change as significant when the difference between the two measurements was more than $50 \%$ in either direction. This choice was based on a formula described by experts in a recent clinical position statement on the management of patients with DTC and TgAb positivity [11].

\section{$\mathrm{dx}$-WBS and pt-WBS}

As indicated in the clinical position statement for the follow-up of the patients with DTC and TgAb [11], the entire group was submitted to dx-WBS [204/212 patients $(96 \%)$ with euthyroidism after rh-TSH stimulation and 8 patients (4\%) after discontinuation of L-T4 therapy]. WBS was performed using a one-head $\gamma$-camera (Apex SPX 4000, Elscint Italia, Milano, Italy) with a high-energy collimator and a sensitivity of $160 \mathrm{cpm} / \mu \mathrm{Ci}$. The scan speed was $10 \mathrm{~cm} / \mathrm{min}$ with a total count of at least $100,000 \mathrm{cpm}$.

$\mathrm{dx}$-WBS was performed 48 hours after administration of a $148 \mathrm{MBq}$ tracer dose of ${ }^{131} \mathrm{I}$. WBS after ${ }^{131} \mathrm{I}$ therapeutic doses (pt-WBS) $(3,330$ $\mathrm{MBq}$ to $5,550 \mathrm{MBq}$ ) was performed 5 days to 10 days after ${ }^{131} \mathrm{I}$ administration.

\section{Neck ultrasound}

Neck US was performed using a color Doppler apparatus (AU 590 Asynchronous, Esaote Biomedica, Firenze, Italy). Central, laterocervical and supraclavear lymph node compartments were also evaluated to exclude the presence of suspicious lymph nodes and, whenever present, a fine needle aspiration biopsy and a $\mathrm{Tg}$ measurement of the washing fluid were performed.

\section{Statistical analysis}

Data were presented as the mean \pm the standard deviation (SD) and the median with an interquartile range (IQR). Sensitivity, specificity and PPV and NPV were calculated for dx-WBS, neck US, stimulated $\mathrm{Tg}$ and $\mathrm{TgAb}$ titer trend in relation to the pt-WBS status.

For each parameter, logistic regression analysis was also conducted to estimate the odds ratios (OR) and the $95 \%$ confidence interval (CI). A p-value less than 0.05 was considered statistically significant. 
Citation: $\quad$ Agate L, Lorusso L, Piaggi P, Bianchi F, Brozzi F, et al. (2016) Role of Thyroglobulin, Neck Ultrasound, Thyroglobulin Antibodies Trend and Diagnostic Whole Body Scan in the Management of Differentiated Thyroid Cancer Patients with Persistent Thyroglobulin Antibodies. J Nucl Med Radiat Ther 7: 317. doi:10.4172/2155-9619.1000317

Page 3 of 7

\section{Results}

Results of basal and stimulated Tg, neck US, dx-WBS and TgAb titer trend

All patients of the study group $(\mathrm{n}=212)$ showed undetectable basal Tg level. The TgAb serum mean titer of the entire group was 182.18 $\mathrm{IU} / \mathrm{ml} \pm 237 \mathrm{IU} / \mathrm{ml}$ (range: $24 \mathrm{IU} / \mathrm{ml}$ to $1663 \mathrm{IU} / \mathrm{ml}$, median: $87 \mathrm{IU} /$ $\mathrm{ml}$ ). As shown in Table 1, stimulated Tg was detectable in $19 / 212$ patients (9\%) (18/204 of those stimulated by rh-TSH and $1 / 8$ of those stimulated by L-T4 withdrawal). The mean Tg peak was $4.2 \pm 6.0$ $\mathrm{ng} / \mathrm{ml}$ (range: 1.18 to $25.50 \mathrm{ng} / \mathrm{ml}$; median: $2.0 \mathrm{ng} / \mathrm{ml}$ ).

\begin{tabular}{|c|c|c|c|c|}
\hline \multirow{2}{*}{$\begin{array}{l}\begin{array}{l}\text { Study group } \\
(\mathrm{n}=212)\end{array} \\
\mathrm{N}^{\circ} \text { of patients } \\
\text { with different } \\
\text { combinations } \\
\text { of results }(\%)\end{array}$} & \multicolumn{4}{|c|}{ Methods used } \\
\hline & $\begin{array}{l}\text { Detectable } \\
\text { stimulated } \text { Tg }^{*}\end{array}$ & $\begin{array}{l}\text { Neck US } \\
\text { (remnant } \\
\text { tissue } \\
\text { and/or } \\
\text { lymph } \\
\text { node mets) }\end{array}$ & $\begin{array}{l}\text { dx-WBS } \\
\text { (remnant tissue } \\
\text { and/or local } \\
\text { mets and/or } \\
\text { distant mets) }\end{array}$ & $\begin{array}{l}\operatorname{TgAb} \text { titer } \\
\text { trend } \\
\text { (increasing } \\
\text { or stable) }\end{array}$ \\
\hline $64(30)$ & - & - & - & + \\
\hline $55(26)$ & - & - & - & - \\
\hline $27(13)$ & - & - & + & - \\
\hline $22(10)$ & - & - & + & + \\
\hline $9(4)$ & + & - & - & + \\
\hline $8(4)$ & - & + & - & + \\
\hline $6(3)$ & - & + & + & + \\
\hline $6(3)$ & + & - & + & + \\
\hline $5(2)$ & - & + & - & - \\
\hline $4(2)$ & - & + & + & - \\
\hline $2(1)$ & + & - & - & - \\
\hline $1(0.5)$ & + & + & + & + \\
\hline $1(0.5)$ & + & - & + & - \\
\hline $1(0.5)$ & - & - & - & unknown \\
\hline $1(0.5)$ & - & - & + & unknown \\
\hline
\end{tabular}

Table 1: Combination of the results of basal and stimulated thyroglobulin (Tg), neck ultrasound (US), diagnostic whole body-scan $(\mathrm{dx}-\mathrm{WBS})$ and thyroglobulin antibodies (TgAb) titer trend in the study group $(\mathrm{n}=212)$.

The neck US identified 24/212 (11.3\%) positive cases. In particular: $14 / 24$ patients $(58.3 \%)$ had remnant thyroid tissue, $2 / 24(8.3 \%)$ had persistent local disease and $8 / 24$ (33.4\%) had cervical lymph node metastases. Cytological examination of the fine needle aspiration biopsies and Tg measurements on washing fluid confirmed the disease diagnoses in the 2 cases with persistence and in the 8 cases with cervical lymph node metastases (Table 1 ). The dx-WBS showed ${ }^{131} \mathrm{I}$ uptake in $68 / 212$ cases $(32.1 \%)$. In particular ${ }^{131} \mathrm{I}$ uptake showed a thyroid remnant tissue in 59/68 patients (86.8\%), cervical lymph node metastases in $3 / 68$ patients (4.4\%), lung metastases in $3 / 68$ patients
(4.4\%) and lymph node in the mediastinal region in $3 / 68$ patients (4.4\%). The $\mathrm{dx}$-WBS was negative in the remaining $144 / 212$ cases (67.9\%). TgAb titer trend was reduced in $94 / 212$ patients (44.3\%), increased in 36 patients (17\%) and stable in 80 patients $(37.7 \%)$. This information was not available for 2 cases (1\%) (Table).

\section{pt-WBS results}

As shown in Figure 1, 68/212 patients (32\%) underwent at least a second ${ }^{131}$ I treatment. Among them 43 were positive at $\mathrm{dx}$-WBS while 25 were negative and treated for other reasons such as a positive stimulated Tg and/or an increasing/stable TgAb titer trend and/or a positive neck US. In some cases a combination of these methods was suggesting the opportunity to treat the patients (Figure 1).

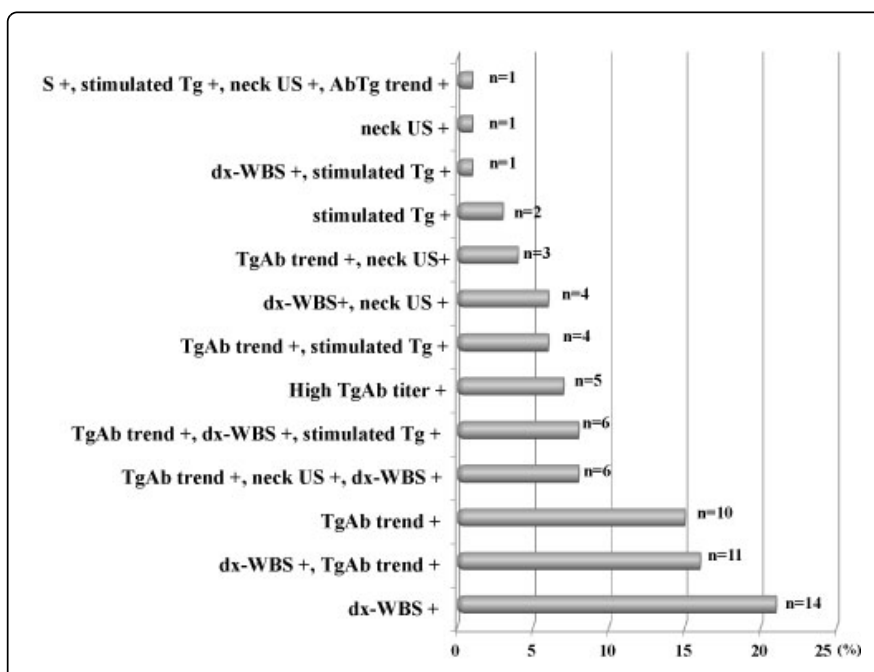

Figure 1: Positive imaging and/or biochemical tests that provided a basis for which patients underwent further treatments with high activities of ${ }^{131} \mathrm{I}$.

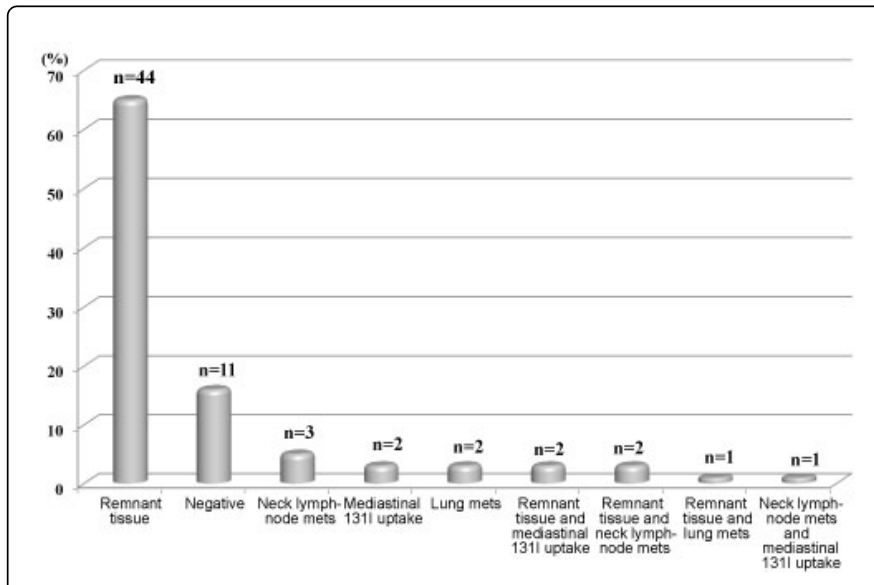

Figure 2: Post high ${ }^{131} \mathrm{I}$ activity whole body scan (pt-WBS) results. The majority of the cases $(n=44)$ were positive only for thyroid bed uptake, which is likely due to post-surgical thyroid remnants.

As shown in Figure 2, the pt-WBS showed the presence of remnant thyroid tissue in 44 patients (65\%) and it was negative in 11 patients (16\%). The remaining 13 patients (19\%) had 131I uptake at pt-WBS in different regions outside the thyroid bed. 
Citation: Agate L, Lorusso L, Piaggi P, Bianchi F, Brozzi F, et al. (2016) Role of Thyroglobulin, Neck Ultrasound, Thyroglobulin Antibodies Trend and Diagnostic Whole Body Scan in the Management of Differentiated Thyroid Cancer Patients with Persistent Thyroglobulin Antibodies. J Nucl Med Radiat Ther 7: 317. doi:10.4172/2155-9619.1000317

Page 4 of 7

\section{Comparison between pt-WBS and other methods results}

As shown in Table 2, stimulated Tg and pt-WBS were both positive or both negative in 14 cases (true positive cases: 12-21; true negative cases: 8-11). In 7 cases they were discordant likely due to false positivity of stimulated $\mathrm{Tg}$ (cases 1-7). In 47 cases the two methods were discordant likely for a low sensitivity of stimulated $\mathrm{Tg}$ (cases 22-68).

\begin{tabular}{|l|l|l|}
\hline Patients & Stimulated Tg & pt-WBS \\
\hline 01-Jul & Positive & Negative \\
\hline 08-Nov & Negative & Negative \\
\hline 12 & Positive & Mediastinal 131I uptake \\
\hline 13 & Positive & Remnant tissue and lung mets \\
\hline $14-21$ & Positive & Remnant tissue \\
\hline $22-23$ & Negative & Remnant tissue and lymph node mets \\
\hline $24-25$ & Negative & Remnant tissue and mediastinal 131I uptake \\
\hline 26 & Negative & Mediastinal 131l uptake \\
\hline $27-29$ & Negative & Lymph node mets \\
\hline 30 & Negative & Lymph node mets and mediastinal 131I uptake \\
\hline $31-32$ & Negative & Lung mets \\
\hline $33-68$ & Negative & Remnant tissue \\
\hline
\end{tabular}

Table 2: results of post high 131I activity whole body scan (pt-WBS) compared to stimulated thyroglobulin (Tg).

\begin{tabular}{|c|c|c|}
\hline Patients & Neck US & pt- WBS \\
\hline $1-2$ & Lymph node mets & Remnant tissue \\
\hline $3-4$ & Lymph node mets & Lymph node mets \\
\hline $5-6$ & Lymph node mets & Remnant tissue and lymph node mets \\
\hline 7 & Lymph node mets & Lung mets \\
\hline $8-43$ & Negative & Remnant tissue \\
\hline $44-53$ & Negative & Negative \\
\hline $54-55$ & Negative & Mediastinal 131/ uptake \\
\hline 56 & Negative & Remnant tissue and lung mets \\
\hline 57 & Negative & Remnant tissue and mediastinal 131 l uptake \\
\hline 58 & Negative & Lymph node mets and mediastinal $131 /$ uptake \\
\hline 59 & Negative & Lung mets \\
\hline 60 & Negative & Lymph node mets \\
\hline $61-66$ & Remnant tissue & Remnant tissue \\
\hline 67 & Remnant tissue & Negative \\
\hline 68 & Remnant tissue & Remnant tissue and mediastinal 131 l uptake \\
\hline
\end{tabular}

Table 3: results of post high 131I activity whole body scan (pt-WBS) compared to neck ultrasound (US).

\begin{tabular}{|c|c|c|}
\hline $\begin{array}{l}\text { Patient } \\
\text { s }\end{array}$ & dx-WBS & pt-WBS \\
\hline $1-3$ & $\begin{array}{l}\text { Cervical Uptake (possible } \\
\text { lymph node mets) }\end{array}$ & Remnant tissue \\
\hline 4 & $\begin{array}{l}\text { Remnant tissue }+ \text { mediastinal } \\
1311 \text { uptake }\end{array}$ & Remnant tissue \\
\hline $5-6$ & Mediastinal 131 l uptake & Mediastinal 131 l uptake \\
\hline 7-8 & Lung mets & Lung mets \\
\hline 9 & Lung mets & Negative \\
\hline 10-38 & Remnant tissue & Remnant tissue \\
\hline $39-40$ & Remnant tissue & $\begin{array}{l}\text { Remnant tissue and lymph node } \\
\text { mets }\end{array}$ \\
\hline 41 & Remnant tissue & Remnant tissue and lung mets \\
\hline $42-43$ & Remnant tissue & Negative \\
\hline $44-51$ & Negative & Negative \\
\hline $52-54$ & Negative & Lymph node mets \\
\hline 55 & Negative & $\begin{array}{l}\text { Lymph node mets and } \\
\text { mediastinal 131l uptake }\end{array}$ \\
\hline $56-57$ & Negative & $\begin{array}{l}\text { Remnant tissue and mediastinal } \\
1311 \text { uptake }\end{array}$ \\
\hline $58-68$ & Negative & Remnant tissue \\
\hline
\end{tabular}

Table 4: results of post high ${ }^{131} \mathrm{I}$ activity whole body scan (pt-WBS) compared to the diagnostic whole body scan $(\mathrm{dx}-\mathrm{WBS})$ results.

\begin{tabular}{|l|l|l|}
\hline Patients & TgAb titer trend & pt- WBS \\
\hline $1-9$ & Increasing/stable & Negative \\
\hline 10 & Decreasing & Negative \\
\hline 11 & Decreasing & Lymph node mets \\
\hline 12 & Decreasing & Remnant tissue and mediastinal 131/ uptake \\
\hline $13-35$ & Decreasing & Remnant tissue \\
\hline $36-37$ & Increasing/stable & Mediastinal 131/ uptake \\
\hline $38-39$ & Increasing/stable & Lymph node mets \\
\hline 40 & Increasing/stable & Lymph node mets and mediastinal 131/ uptake \\
\hline $41-42$ & Increasing/stable & Lung mets \\
\hline 43 & Increasing/stable & Remnant tissue and and mediastinal 131I uptake \\
\hline $44-45$ & Increasing/stable & Remnant tissue and lymph node mets \\
\hline 46 & Increasing/stable & Remnant tissue and lung mets \\
\hline $47-67$ & Increasing/stable & Remnant tissue \\
\hline * Information about TgAb trend was available in 67/68 treated patients. \\
\hline 40 & & \\
\hline 4
\end{tabular}

Table 5: results of post high ${ }^{131} \mathrm{I}$ activity whole body scan (pt-WBS) compared to thyroglobulin antibodies (TgAb) titer trend evaluation. 
Citation: $\quad$ Agate L, Lorusso L, Piaggi P, Bianchi F, Brozzi F, et al. (2016) Role of Thyroglobulin, Neck Ultrasound, Thyroglobulin Antibodies Trend and Diagnostic Whole Body Scan in the Management of Differentiated Thyroid Cancer Patients with Persistent Thyroglobulin Antibodies. J Nucl Med Radiat Ther 7: 317. doi:10.4172/2155-9619.1000317

Page 5 of 7

As shown in Table 3, neck US and pt-WBS were both positive and both negative in 24 cases (true positive cases: 1-7, 61-66 and 68; true negative cases: 44-53). In 1 case they were discordant likely due to a false positivity of neck US (case 67). In 43 cases the two methods were discordant likely for a low sensitivity of stimulated $\mathrm{Tg}$ (cases 8-43 and 54-60).

As reported in Table 4, dx-WBS and pt-WBS were both positive and both negative in 48 cases (true positive cases: 1-8 and 10-41; true negative cases: 44-51).

In 3 cases they were discordant likely due to a false positive dx-WBS (cases 9 and 42-43). In 17 cases the two methods were discordant likely for a low sensitivity of dx-WBS (cases 52-68).
As shown in Table 5, TgAb titer trend evaluation and pt-WBS were both positive and both negative in 33 cases (true positive cases: 36-67; true negative cases: 10 ).

In 9 cases they were discordant likely due to a false positivity of $\mathrm{TgAb}$ titer trend (cases 1-9). In 25 cases the two methods were discordant likely for a low sensitivity of TgAb titer trend (cases 11-35).

A summary of true and false positive and true and false negative cases of the four methods was reported in Table 6.

\begin{tabular}{|l|l|l|l|l|}
\hline & True positive cases (\%) & False positive cases (\%) & True negative cases (\%) & False negative cases (\%) \\
\hline dx-WBS & $40 / 68(59)$ & $3 / 68(4)$ & $8 / 68(12)$ & $17 / 68(25)$ \\
\hline Stimulated Tg & $10 / 68(15)$ & $7 / 68(10)$ & $4 / 68(6)$ & $47 / 68(69)$ \\
\hline Neck US & $14 / 68(21)$ & $1 / 68(1)$ & $10 / 68(15)$ & $43 / 68(63)$ \\
\hline TgAb titer trend & $32 / 67^{*}(48)$ & $9 / 67^{*}(13)$ & $1 / 67^{\star}(2)$ & $25 / 67^{\star}(37)$ \\
\hline * information about TgAb trend was available in $67 / 68$ treated patients & & \\
\hline
\end{tabular}

Table 6: summary of true positive, false positive, true negative and false negative cases of diagnostic whole body scan (dx-WBS), simulated thyroglobulin (Tg), neck ultrasound (US) and thyroglobulin antibodies (TgAb) titer trend evaluation.

\section{Sensitivity, specificity, and positive and negative predictive values for $\mathrm{dx}$-WBS and other diagnostic methods}

The sensitivity, specificity, PPV and NPV for dx-WBS and other diagnostic methods are reported in Table 7. dx-WBS sensitivity and specificity were $70 \%$ and $72 \%$, respectively. Neck US was the only method with a greater specificity than dx-WBS (91\% vs $72 \%)$, although it had a lower sensitivity $(24 \%)$.
As expected, based on the $\mathrm{TgAb}$ positivity, stimulated Tg sensitivity was confirmed to be very low in this study group (18\%). The low sensitivity and specificity (56\% and $10 \%$, respectively) for the increasing or stable $\mathrm{TgAb}$ titer trend when it was considered alone should also be noted.

\begin{tabular}{|c|c|c|c|c|}
\hline Diagnostic tools & $\begin{array}{l}\text { Sensitivity, \% } \\
(\mathrm{Cl}, \%)\end{array}$ & $\begin{array}{l}\text { Specificity, \% } \\
(\mathrm{Cl}, \%)\end{array}$ & $\begin{array}{l}\text { PPV, \% } \\
(\mathrm{CI}, \%)\end{array}$ & $\begin{array}{l}\text { NPV, \% } \\
(\mathrm{CI}, \%)\end{array}$ \\
\hline$d x-W B S$ & $70(57-81)$ & $72(39-94)$ & $93(81-98)$ & $32(15-53)$ \\
\hline Stimulated Tg & $18(9-30)$ & $63(31-89)$ & $71(42-92)$ & $13(5-25)$ \\
\hline Neck US & $24(14-38)$ & $91(59-100)$ & $93(68-100)$ & $18(9-32)$ \\
\hline $\operatorname{TgAb}$ titer trend & $56(42-69)$ & $10(0-44)$ & $78(62-89)$ & $4(0-20)$ \\
\hline Stimulated Tg+dx-WBS & $75(62-86)$ & $45(17-77)$ & $88(75-95)$ & $26(9-51)$ \\
\hline Stimulated Tg+neck US & $42(29-56)$ & $64(31-89)$ & $86(67-96)$ & $18(7-33)$ \\
\hline $\operatorname{TgAb}$ titer trend $+\mathrm{dx}-$ WBS & $88(76-94)$ & $0(0-31)$ & $83(71-92)$ & $0(0-41)$ \\
\hline $\operatorname{TgAb}$ titer trend+neck US & $65(51-77)$ & $10(0-44)$ & $80(66-91)$ & $5(0-24)$ \\
\hline dx-WBS+stimulated Tg+neck US & $82(70-91)$ & $45(17-77)$ & $89(77-96)$ & $33(12-62)$ \\
\hline $\begin{array}{l}\text { dx-WBS+stimulated } T g+\text { neck US+TgAb titer } \\
\text { trend }\end{array}$ & $93(83-98)$ & $0(0-31)$ & $84(73-92)$ & $0(0-60)$ \\
\hline
\end{tabular}

Table 7: sensitivity, specificity, positive predictive value (PPV) and negative predictive value (NPV) and 95\% intervals of confidence (CI) of diagnostic whole body scan (dx-WBS), stimulated thyroglobulin (Tg), thyroglobulin antibodies (TgAb) titer trend (increasing/stable) and neck ultrasound (US) considered alone and in combination with each other. 
Although sensitivity increased from $70 \%$ to $93 \%$ when $\mathrm{dx}$-WBS was associated with stimulated $\mathrm{Tg}$ measurements, $\mathrm{TgAb}$ titer trend evaluations and neck US, the best single method able to detect posttreatment 131I uptake was $\mathrm{dx}$-WBS $(\mathrm{OR}=6.3,95 \%$ CI: 1.48 to 26.6 , $\mathrm{p}=0.01)$.

Stimulated Tg, neck US and TgAb titer trend evaluation were not statistically significant to detect patients with post-treatment 131I uptake ( $\mathrm{p}=0.17, \mathrm{p}=0.28$, and $\mathrm{p}=0.07$, respectively).

\section{Discussion}

The important role of serum $\mathrm{Tg}$ as a post-operative biochemical tumor-marker in patients with DTC has been well-established. In particular its high sensitivity and NPV when used in conjunction with neck US for disease detection has been proved [14]. One major limitation in its use due to interference from $\mathrm{TgAb}$, which are found in approximately $25 \%$ of DTC patients. Based on this interference, current guidelines for the management of DTC patients recommend a $\mathrm{TgAb}$ measurement with every Tg measurement [6].

Because $\operatorname{TgAb}$ positivity makes $\mathrm{Tg}$ values unreliable for understanding disease status, a group of experts recently proposed a clinical position statement where they suggest the use of the TgAb titer as a surrogate marker for the disease. In particular, they suggest the evaluation of the titer trend during DTC patient follow-ups. For this subgroup of patients, in addition to the TgAb titer trend evaluation and neck US, dx-WBS is also suggested to detect structural disease, especially outside the thyroid bed [11].

The aim of our study was to identify the best method among stimulated $\mathrm{Tg}, \mathrm{TgAb}$ titer trend, neck US and $\mathrm{dx}$-WBS for detecting the presence of persistent diseases in a group of DTC patients with TgAb.

Our study demonstrated that stimulated Tg (either after levotyroxine withdrawal or rh-TSH stimulation) was detectable in $9 \%$ of patients despite $\mathrm{TgAb}$ positivity at the first control after the initial treatment (i.e. total thyroidectomy and thyroid remnant ablation with 131I). This finding showed that in some cases, despite the presence of high $\mathrm{TgAb}$ levels, the interference is not complete and serum $\mathrm{Tg}$ can be detected, especially after TSH stimulation $[16,17]$. However, the grade of $\mathrm{TgAb}$ interference cannot be quantified and the Tg measurements for this subgroup of patients remains unreliable for identifying cured DTC patients, although its positive diagnostic role has been confirmed.

Because the neck is the most frequent site for persistent/recurrent disease in DTC patients, it is well-established that neck US is the best method to detect local persistent disease or the persistence of lymph node metastases [18]. In our study, although neck US had a very low $\mathrm{NPV}$, which is primarily due to its inability to detect metastatic disease outside of the neck, it had a high PPV (93\%), confirming that it is also a good method for detecting neck disease/remnant thyroid tissue in this subgroup of patients. It should also be taken into account that, when a suspicious lesion is found by neck US, a confirming diagnosis can be obtained with a fine needle aspiration biopsy and a $\mathrm{Tg}$ measurement from the washing fluid. Our study, as well as other previous studies [19], has identified no relevant TgAb interference to $\mathrm{Tg}$ measurements in the washing fluid. It should also be kept in mind that small lymph nodes metastases (cases 7 and 58 of our series) may not be able to take up ${ }^{131} \mathrm{I}$, but their metastatic nature, as reported above, can be confirmed by cytology and $\mathrm{Tg}$ measurement in the washing fluid.
Regarding the $\mathrm{TgAb}$ titer trend, $44.5 \%$ of patients had a decreasing titer trend and $54.5 \%$ had an increasing/stable titer trend. In particular, an increasing/stable titer trend alone was found in 30\% of patients, while in the remaining $24.7 \%$ it was associated with at least one other positive method ( $10 \%$ with positive $\mathrm{dx}$-WBS and $14.7 \%$ with positivity based on the other methods considered). When the TgAb titer trend was considered alone, a high PPV was identified (78\%) despite the low NPV (4\%). In our opinion, the low NPV can be explained with results obtained in a previous study by Chiovato et al. [20]. These authors demonstrated that the persistence of thyroid autoimmunity remains until the complete removal of thyroid antigens (represented by both normal and tumoral thyroid cells); the median disappearance time for $\mathrm{TgAb}$ is 3 years. In some unpublished data, we have also observed that some DTC patients need several years (up to 20) for total TgAb disappearance in the absence of active therapy. In the present study, especially for those patients with a stable titer trend, the time interval between the initial treatment and our observation was probably not enough to allow a significant decrease in $\operatorname{TgAb}$, as suggested by Chiovato et al. [20]. When the TgAb titer trend evaluation was associated with dx-WBS, the PPV increased to $83 \%$ at the expense of the NPV, which was further reduced. In the same way, when the TgAb titer trend was associated with neck US, the PPV was higher than when the $\operatorname{TgAb}$ titer trend was considered alone.

$\mathrm{dx}$-WBS is no longer used in the follow-up for patients with lowrisk DTC because it is less sensitive than serum stimulated $\mathrm{Tg}$ [21]. However, this is applicable only when the Tg levels, both basal and after endogenous or exogenous TSH stimulation, were reliable and thus, in the absence of TgAb interference. As indicated in the current guidelines [6], dx-WBS still plays an important role in DTC patients with TgAb and this was confirmed by our study. In fact, dx-WBS was able to detect $40 / 68$ (59\%) true positive cases, including 2 patients with mediastinal ${ }^{131} \mathrm{I}$ uptake and 2 patients with lung disease.

According to these results, dx-WBS showed the best combination between sensitivity and specificity (70\% and $72 \%$, respectively) and between PPV and NPV (93\% and 32\%, respectively). It should be noted that only when we considered all four methods together did the sensitivity increase up to $93 \%$, although at the expense of specificity.

Similar to the findings of Rosario et al. [13], we found that the combination of $\mathrm{dx}$-WBS, stimulated $\mathrm{Tg}$ and neck US without $\mathrm{TgAb}$ titer trend showed the best compromise between sensitivity and specificity. This result is in contrast with the suggestion of experts to use $\mathrm{TgAb}$ trend as a surrogate for serum Tg. Very likely, the use of the $\mathrm{TgAb}$ trend is more useful during long-term follow-up than immediately after the initial treatment for the reasons mentioned above.

A main limitation of this study is that we considered a ${ }^{131}$ I uptake in the thyroid bed a positive result and 12 patients were treated only for this reason. Whether ${ }^{131}$ I uptake limited at the thyroid bed requires or not to be always treated is still a matter of discussion. The ${ }^{131} \mathrm{I}$ treatment should be better reserved to cases with ${ }^{131}$ I uptake due to lymphnodes metastases other than to normal remnant. Since the planar WBS cannot distinguish the uptake due to the remnant from those due to small local lymphnodes, the use of single photon emission computed tomography/computed tomography (SPECT-CT) is strongly suggested since it allows a better identification of the uptake site, as it has been recently demonstrated $[22,23]$.

In conclusion, the present study demonstrated that $\mathrm{dx}$-WBS plays an important role in detecting DTC patients with circulating TgAb 
Citation: Agate L, Lorusso L, Piaggi P, Bianchi F, Brozzi F, et al. (2016) Role of Thyroglobulin, Neck Ultrasound, Thyroglobulin Antibodies Trend and Diagnostic Whole Body Scan in the Management of Differentiated Thyroid Cancer Patients with Persistent Thyroglobulin Antibodies. J Nucl Med Radiat Ther 7: 317. doi:10.4172/2155-9619.1000317

Page 7 of 7

that need a further ${ }^{131}$ I treatment, either when it is considered alone or in association with other methods and particularly during the first couple of years of follow-up. However, when a suspicious persistent disease is present and the dx-WBS is negative, other imaging methods, such as a CT scan or FDG-PET, should be considered. Finally, from this study, it appears that the TgAb titer trend does not add any useful information about the disease status in the first two years after initial treatment.

\section{Acknowledgments:}

Supported in part by Grants from Associazione Italiana Ricerca sul Cancro (AIRC Investigator grant 2014, project code 15431).

\section{References}

1. Spencer CA, LoPresti JS, Fatemi S, Nicoloff JT (1999) Detection of residual and recurrent differentiated thyroid carcinoma by serum thyroglobulin measurement. Thyroid 9:435-441.

2. Pacini F, Mariotti S, Formica N, Elisei R, Anelli S, et al. (1988) Thyroid autoantibodies in thyroid cancer: incidence and relationship with tumour outcome. Acta Endocrinol (Copenh) 119: 373-380.

3. Hollowell JG, Staehling NW, Flanders WD, Hannon WH, Gunter EW, et al. (2002) Serum TSH, T(4), and thyroid antibodies in the United States population (1988 to 1994): National Health and Nutrition Examination Survey (NHANES III). J Clin Endocrinol Metab 87: 489-499.

4. Spencer CA, Wang CC (1995) Thyroglobulin measurement. Techniques, clinical benefits, and pitfalls. Endocrinol Metab Clin North Am 24: 841-863.

5. Mariotti S, Cupini C, Giani C, Lari R, Rolleri E, et al. (1982) Evaluation of a solid-phase immunoradiometric assay (IRMA) for serum thyroglobulin: effect of anti-thyroglobulin autoantibody. Clin Chim Acta 123: 347-355.

6. Haugen BRM, Alexander EK, Bible KC, Doherty G, Mandel SJ, et al. (2016) 2015 American Thyroid Association Management Guidelines for Adult Patients with Thyroid Nodules and Differentiated Thyroid Cancer. Thyroid 26: 1-33.

7. Pacini F, Schlumberger M, Dralle H, Ilisea R, Smith Y, et al. (2008) European consensus on the management of patients with differentiated carcinoma of the thyroid from follicular epithelium. Vestn Khir Im I I Grek 167: 52-56.

8. Chung JK, Park YJ, Kim TY, So Y, Kim SK, et al. (2002) Clinical significance of elevated level of serum antithyroglobulin antibody in patients with differentiated thyroid cancer after thyroid ablation. Clin Endocrinol (Oxf) 57: 215-221

9. Spencer CA, Takeuchi M, Kazarosyan M, Wang CC, Guttler RB, et al (1998) Serum thyroglobulin autoantibodies: prevalence, influence on serum thyroglobulin measurement, and prognostic significance in patients with differentiated thyroid carcinoma. J Clin Endocrinol Metab 83: 1121-1127.

10. Rubello D, Casara D, Girelli ME, Piccolo M, Busnardo B (1992) Clinical meaning of circulating antithyroglobulin antibodies in differentiated thyroid cancer: a prospective study. J Nucl Med 33: 1478-1480.
11. Verburg FA, Luster M, Cupini C, Chiovato L, Duntas L, et al. (2013) Implications of thyroglobulin antibody positivity in patients with differentiated thyroid cancer: a clinical position statement. Thyroid 23: 1211-1225.

12. Verburg FA, Stokkel MP, Duren C, Verkooijen RB, Mader U, et al. (2010) No survival difference after successful (131)I ablation between patients with initially low-risk and high-risk differentiated thyroid cancer. Eur J Nucl Med Mol Imaging 37: 276-283.

13. Rosario PW, Mineiro Filho AF, Lacerda RX, dos Santos DA, Calsolari MR (2012) The value of diagnostic whole-body scanning and serum thyroglobulin in the presence of elevated serum thyrotropin during follow-up of anti-thyroglobulin antibody-positive patients with differentiated thyroid carcinoma who appeared to be free of disease after total thyroidectomy and radioactive iodine ablation. Thyroid 22: 113-116.

14. Pacini F, Molinaro E, Lippi F, Castagna MG, Agate L, et al. (2001) Prediction of disease status by recombinant human TSH-stimulated serum $\mathrm{Tg}$ in the postsurgical follow-up of differentiated thyroid carcinoma. J Clin Endocrinol Metab 86: 5686-5690.

15. de Meer SG, Vriens MR, Zelissen PM, Borel Rinkes IH, de Keizer B (2011) The role of routine diagnostic radioiodine whole-body scintigraphy in patients with high-risk differentiated thyroid cancer. J Nucl Med 52: 56-59.

16. Cubero JM, Rodriguez-Espinosa J, Gelpi C, Estorch M, Corcoy R (2003) Thyroglobulin autoantibody levels below the cut-off for positivity can interfere with thyroglobulin measurement. Thyroid 13: 659-661.

17. Rosario PW, Maia FF, Fagundes TA, Vasconcelos FP, Cardoso LD, et al. (2004) Antithyroglobulin antibodies in patients with differentiated thyroid carcinoma: methods of detection, interference with serum thyroglobulin measurement and clinical significance. Arq Bras Endocrinol Metabol 48: 487-492.

18. Frasoldati A, Pesenti M, Gallo M, Caroggio A, Salvo D, et al. (2003) Diagnosis of neck recurrences in patients with differentiated thyroid carcinoma. Cancer 97: 90-96.

19. Boi F, Baghino G, Atzeni F, Lai ML, Faa G, et al. (2006) The diagnostic value for differentiated thyroid carcinoma metastases of thyroglobulin (Tg) measurement in washout fluid from fine-needle aspiration biopsy of neck lymph nodes is maintained in the presence of circulating anti-Tg antibodies. J Clin Endocrinol Metab 91: 1364-1369.

20. Chiovato L, Latrofa F, Braverman LE, Pacini F, Capezzone M, et al. (2013) Disappearance of humoral thyroid autoimmunity after complete removal of thyroid antigens. Ann Intern Med 139: 346-351.

21. Pacini F, Molinaro E, Castagna MG, Agate L, Elisei R, et al. Recombinant human thyrotropin-stimulated serum thyroglobulin combined with neck ultrasonography has the highest sensitivity in monitoring differentiated thyroid carcinoma. J Clin Endocrinol Metab 88: 3668-3673.

22. Agrawal K, Bhattacharya A, Mittal BR (2015) Role of single photon emission computed tomography/computed tomography in diagnostic iodine-131 scintigraphy before initial radioiodine ablation in differentiated thyroid cancer. Indian J Nucl Med 30: 221-226.

23. Zeuren R, Biagini A, Grewal RK, Randolph GW, Kamani D, et al. (2015) RAI thyroid bed uptake after total thyroidectomy: A novel SPECT-CT anatomic classification system. Laryngoscope 125: 2417-2424. 